\title{
ON THE INDEX OF A QUADRATIC FORM
}

Jonathan Wild, Prince Albert, Sask.

Given a vector space $V=\{x, y, \ldots\}$ over an arbitrary field. In $\mathrm{V}$ a symmetric bilinear form $(x, y)$ is given. A subspace $W$ is called totally isotropic $[t . i]$ if $(x, y)=0$ for every pair $\mathrm{x}$ W, $\mathrm{y}$ W.

Let $\mathrm{V}_{\mathrm{n}}$ and $\mathrm{V}_{\mathrm{m}}$ be two t.i. subspaces of $\mathrm{V} ; \mathrm{n}<\mathrm{m}$. Lower indices always indicate dimensions. It is a well known and fundamental fact of analytic geometry that there exists a $t . i$. subspace $\mathrm{W}_{\mathrm{m}}$ of $\mathrm{V}$ containing $\mathrm{V}_{\mathrm{n}}$ [cf. Dieudonné: Les Groupes classiques, P. 18]. As no simple direct proof seems to be available, we propose to supply one.

We first consider the case that $V_{n} \cap V_{m}=O$. Thus $V_{n}$ and $V_{m}$ span a subspace $V_{n+m}$. The vectors of $V_{n+m}$ orthogonal to $\mathrm{V}_{\mathrm{n}}$ form a subspace $\mathrm{W}$.

Every vector of $V_{n+m}$, in particular every vector $x \in W$ permits a decomposition $x=y+z ; y \in V_{n}, z \in V_{m}$. Suppose also $x^{\prime}=y^{\prime}+z^{\prime} \in W ; y^{\prime} \in V_{n}, z^{\prime} \in V_{m}$. Since $V_{n}$ and $V_{m}$ are t.i., we have $\left(y, y^{\prime}\right)=\left(z, z^{\prime}\right)=0$. By the definition of $W, O=\left(y, x^{\prime}\right)=$ $\left(y, y^{\prime}+z^{\prime}\right)=\left(y, y^{\prime}\right)+\left(y, z^{\prime}\right)=\left(y, z^{\prime}\right)$. Similarly $\left(y^{\prime}, z\right)=0$. Hence$$
\left(x, x^{\prime}\right)=\left(y+z, y^{\prime}+z^{\prime}\right)=\left(y, y^{\prime}\right)+\left(y, z^{\prime}\right)+\left(z, y^{\prime}\right)+\left(z, z^{\prime}\right)
$$$$
=0+0+0+0=0 \text {. }
$$

Thus $W$ is t.i. As $\operatorname{dim} W \geqslant m$ and $V_{n} \subset W$, this disposes of our special case.

Assume now $V_{n} \cap V_{m}=V_{d}$. Thus $V_{n}$ and $V_{m}$ permit direct decompositions $\mathrm{V}_{\mathrm{n}}=\mathrm{V}_{\mathrm{d}}+\mathrm{V}_{\mathrm{n}-\mathrm{d}}, \mathrm{V}_{\mathrm{m}}=\mathrm{V}_{\mathrm{d}}+\mathrm{V}_{\mathrm{m}-\mathrm{d}}$. From the above, there exists a t.i. subspace $W_{m-d}$ satisfying

(1) $\quad V_{n-d} \subset w_{m-d} \subset V_{n_{-}-d}+V_{m-d}$.

Since $V_{d} \curvearrowright\left(V_{n-d}+V_{m-d}\right)=0$, we also have $V_{d} \cap W_{m-d}=O$ and (2) $\quad v_{n}=v_{d}+v_{n-d} \subset v_{d}+w_{m-d}=w_{m}$.

Let $y \in V_{d}, z \in W_{m-d}$. By (1), $z=r+s$ where $r \in V_{n-d}$, $s \in V_{m-d}$. Since $y$ and $r$ [y and $\left.s\right]$ lie in the t.i. subspace $\mathrm{V}_{\mathrm{n}}\left[\mathrm{V}_{\mathrm{m}}\right]$, we have $(\mathrm{y}, \mathrm{z})=(\mathrm{y}, \mathrm{r})+(\mathrm{y}, \mathrm{s})=\mathrm{O}+\mathrm{O}=0$. Thus $\mathrm{V}_{\mathrm{d}}$ and $\mathrm{W}_{\mathrm{m}-\mathrm{d}}$ are orthogonal.

By $(2)$, any two vectors $x, x^{\prime}$ of $W_{m}$ permit decompositions $x=y+z, x^{\prime}=y^{\prime}+z^{\prime}$ where $y, y^{\prime} \in V_{d} ; z, z^{\prime} \in W_{m-d}$. From the above $\left(y, z^{\prime}\right)=\left(z, y^{\prime}\right)=0$. Since $V_{d}$ and $W_{m-d}$ are t.i., we also have $\left(y, y^{\prime}\right)=\left(z, z^{\prime}\right)=0$. Thus $\left(x, x^{\prime}\right)=\left(y, y^{\prime}\right)+\left(y, z^{\prime}\right)+\left(z, y^{\prime}\right)+$ $\left(z, z^{\prime}\right)=O$ and $W_{m}$ is $t . i$. 